\title{
CONF-9510203--1
}

\section{A Delta Configured Auxiliary Resonant Snubber Inverter}

\author{
J. S. Lai, R. W. Young, Sr., G. W. Ott, Jr., J. W. McKeever \\ Oak Ridge National Laboratory ${ }^{*}$ \\ Engineering Technology Division \\ Bldg. K-1008F, M/S 7258 \\ Oak Ridge, Tennessee 37831-7258
}

\author{
F. Z. Peng \\ University of Tennessee, Knoxville \\ Oak Ridge National Laboratory ${ }^{*}$ \\ Bldg. K-1008F, M/S 7258 \\ Oak Ridge, Tennessee 37831-7258
}

\begin{abstract}
A delta $(\Delta)$ configured auxiliary resonant snubber inverter is developed to overcome the voltage floating problem in a wye ( $Y$ ) configured resonant snubber inverter. The proposed inverter is to connect auxiliary resonant branches between phase outputs to avoid a floating point voltage which may cause over-voltage failure of the auxiliary switches. Each auxiliary branch consists of a resonant inductor and a reverse blocking auxiliary switch. Instead of using an anti-paralleled diode to allow resonant current to flow in the reverse direction, as in the Y-configured version, the resonant branch in the $\Delta$ configured version must block the negative voltage, typically done by a series diode. This paper shows single-phase and three-phase versions of $\Delta$-configured resonant snubber inverters and describes in detail the operating principle of a single-phase version. The extended three-phase version is proposed with non-adjacent state space vector modulation. For hardware implementation, a single-phase 1-kW unit and a three-phase $100-\mathrm{kW}$ unit were built to prove the concept. Experimental results show the superiority of the proposed topology.
\end{abstract}

\section{INTRODUCTION}

Auxiliary resonant snubber based inverters can be configured in different versions $[1 \sim 5]$. The basic principle of such inverters is to use an auxiliary active switching device along with lossless passive snubber components to achieve soft switching. The parasitic inductance and stray capacitance are utilized as a part of the resonant components. There is no over-voltage or over-current penalty in the main inverter switches. This type of inverter generally achieves high efficiency power conversions in a cost effective way of soft switching.

There are some minor problems which exist in the different versions of resonant snubber based inverters. The ordinary resonant snubber inverter or auxiliary resonant commutated pole (ARCP) inverter, described in [2, 3], requires a stiff dc link capacitor bank which is center tapped to accomplish commutation. The resonant transition inverter, described in $[4,5]$, requires many transitions to achieve desired state changes. It also requires voltage clamping devices to prevent over-voltage across the auxiliary resonant switch during resonant current resetting. The $\mathrm{Y}$-configured resonant snubber inverter, described in [1], is similar to the resonant transition inverter in that it requires a clamping diode or resonant current sensors along with a precise control to prevent over-voltage across the auxiliary resonant switch.

To avoid using additional bulky capacitors and generating over-voltage in the resonant switches, a delta $(\Delta)$ configured resonant snubber inverter, shown in Fig. 1, is proposed. The proposed inverter has auxiliary resonant branches connected between the different phase-leg outputs to avoid a floating point voltage which may cause overvoltage failure of the auxiliary switches. Instead of using an anti-paralleled diode to allow resonant current flow in the reverse direction as in the $\mathrm{Y}$-configured version, the resonant branch in the $\Delta$-configured version uses a blocking diode to block the negative voltage. Each auxiliary branch consists of a resonant inductor and a reverse blocking auxiliary switch. Compared to the auxiliary resonant commutated pole inverter, the proposed scheme does not need a center tapped connection from the dc link capacitor bank. Compared to the $Y$-configured scheme, the advantages of the $\Delta$-configured scheme are (1) avoidance of over-voltage ringing due to slow recovery diodes and parasitic components in the auxiliary resonant circuit and (2) suitability for multi-phase operation without having circulating currents between the off-state branch and its corresponding output load.

In this paper, the operating principie and associated problems of the $\mathrm{Y}$-configured resonant snubber inverter are briefly described. Then a detailed description of the operation of the $\Delta$-configured resonant snubber circuit is presented. The operating principle was first verified by computer simulation, and the actual performance was then evaluated with a single-phase $1-\mathrm{kW}$ unit and a three-phase $100-\mathrm{kW}$ unit. Experimental results show superior performance with an efficiency improvement, turn-off $d v / d t$ rate reduction, and electromagnetic interference (EMI) reduction.

\footnotetext{
* Prepared by the Oak Ridge National Laboratory, Oak Ridge, Tennessee 37831-7280, managed by Lockheed Martin Energy Systems, Inc. for the U. S. Department of Energy under contract DE-AC05-84OR21400.

The submitted manuscript has been authored by Oak Ridge National Laboratory, Oak Ridge, Tennessee 37831-7280. managed by Lockheed Martin Energy Systems. Inc. for the U. S. Department of Energy under contract No. DE-AC05-84OR21400. Accordingly, the U. S, Government retains a nonexclusive. royalty-free license to publish or reproduce the published form of this contribution, or allow others to do so. for $U$. S. Government purposes.
}

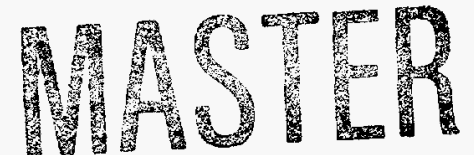




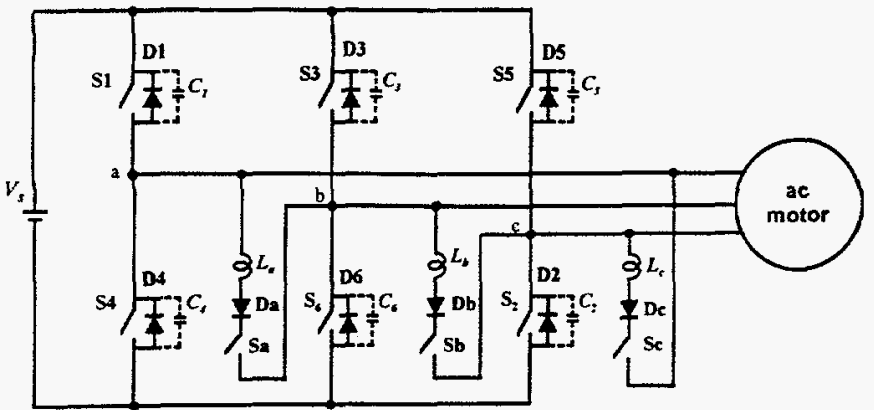

Fig. 1. The proposed auxiliary resonant snubber inverter showing three auxiliary switches connected in delta between output terminals.

\section{Circuit Operation and Problems of the Y- CONFIGURED RESONANT SNUBBER INVERTER}

Fig. 2 shows the Y-configured resonant snubber inverter which consists of a standard six-bridge inverter and three auxiliary branches which are connected in Y-configuration. The standard six-bridge inverter consists of six power semiconductor switches, S1 S6, and their anti-parallel diodes, D1 D6. Capacitors, $C_{T} \sim C_{6}$, can be externally added or simply internal parasitics. The purpose of adding external capacitors is to slow down the voltage rise rate during turnoff so that turn-off loss can be reduced and the turn-off voltage spike can be eliminated. The internal parasitic capacitance is normally not sufficient to avoid excessive turnoff voltage rise rate $(\mathrm{dv} / \mathrm{dt})$.

Each auxiliary branch consists of an auxiliary switch, an anti-parallel diode, and a resonant inductor. The resonant current is bi-directional; therefore, turning on Sa enables resonant current to flow through inductors $L_{a}$ and $L_{b}$ and diode $\mathrm{Db}$. Similarly, turning on $\mathrm{Sb}$ allows resonant current to flow through inductors $L_{b}$ and $L_{c}$ and diode Dc, and turning on $\mathrm{Sc}$ enables resonant current to flow through inductors $L_{c}$ and $L_{a}$ and diode $\mathrm{Da}$.

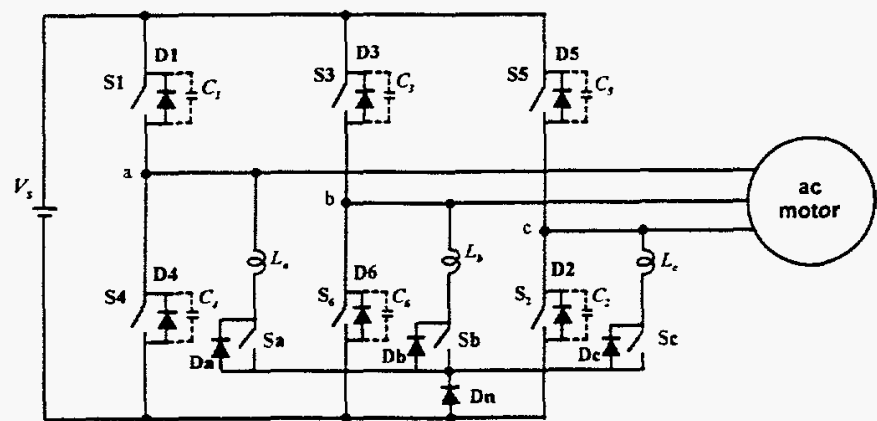

Fig. 2. The $\mathrm{Y}$-connected version of the auxiliary resonant snubber inverter.

The problems with this circuit topology are the same as those in the resonant transition inverters $[4,5]$ and are listed below.

1) There will be over-voltage across the auxiliary switch if the center point of the $\mathrm{Y}$-connection is not connected to the main six-bridge inverter circuit (floating). The voltage across the auxiliary switch will exceed the supply voitage which can cause over-voltage failure. One way of preventing overvoltage is to add a clamping diode, $D_{n}$, between the main circuit ground and the $Y$-connection common point. When resonance causes the voltage at the $\mathrm{Y}$-connection common point to decrease below zero, the clamping diode, $D_{n}$, conducts, and the voltage across the resonant switch is suppressed. An alternative way of preventing over-voltage is to allow the resonant current to flow in the opposite-side resonant switches and then turn them off when the resonant current swings back to zero. The later approach requires current sensors in the resonant branches and a precise control.

2) There will be circulating current in the off phase when the main inverter circuit conducts current in two of the three phases. The off phase may have a circulating current because the load voltage is unknown and current can flow into this phase through the anti-parallel diode. This case occurs mainly in brushless dc motor drives which conduct only two phases at a time, and the back emf tends to circulate current through resonant branches which are at off-state.

\section{PRinCiPle OF THE DELTA CONFIGURED RESONANT SNUBBER INVERTER}

Fig. 1 illustrates the proposed $\Delta$-configured auxiliary resonant snubber structure for a three-phase motor drive application. The six-bridge inverter shown is the same as a traditional circuit containing S1 S6, D1 D6, and $C_{1} \sim C_{6}$. Capacitors, $C_{1} \sim C_{6}$, can be either external or internal. Each auxiliary resonant branch circuit is connected between two inverter output terminals, i.e., $\mathbf{a}-\mathbf{b}, \mathbf{b}-\mathbf{c}, \mathbf{c}-\mathbf{a}$. A basic auxiliary branch consists of an auxiliary switch and an inductor. A blocking diode is in series with the auxiliary switch to protect the switch from reverse voltage breakdown. If the auxiliary switch has built-in reverse blocking capability, then the blocking diode is not needed.

The three-phase inverter operation can be treated as the extension of a single-phase inverter operation. For the resonant operation between phases $a$ and $b$, turning on Sa will build up a resonant current from $a$ to $b$, while turning on $\mathrm{Sb}$ and $\mathrm{Sc}$ simultaneously will build up a resonant current from $\mathbf{b}$ to $\mathbf{a}$. The same approach can be applied to phases $\mathbf{b}$ and $\mathbf{c}$ and phases $\mathbf{c}$ and $\mathbf{a}$.

\section{A. Single-Phase Circuit Operation}

A single-phase full-bridge inverter, shown in Fig. 3, contains four main switches, S1 $\mathrm{S} 4$, anti-paralleled diodes, D1 D4, and resonant capacitors, $C_{1} \sim C_{t}$. There are two switch pairs, S1 and S4, and their diagonal pair, S2 and S3. Two anti-paralleled resonant branches are connected across the output terminals. The load is assumed to be a resistor, $R_{v}$, in series with an inductor, $L_{0}$. Each resonant branch circuit contains an inductor in series with a blocking diode and a switch. For resonant branch one, the circuit operation consists of turning on switch $\mathrm{Sr} 1$ to establish a current, $I_{L r l}$, in $L_{r /}$ before turning off the main switches S1 and S4. Similarly 


\section{DISCLAMMER}

This report was prepared as an account of work sponsored by an agency of the United States Government. Neither the United States Government nor any agency thereof, nor any of their employees, makes any warranty, express or implied; or assumes any legal liability or responsibility for the accuracy, completeness, or usefulness of any information, apparatus, product, or process disclosed, or represents that its use would not infringe privately owned rights. Reference herein to any specific commercial product, process, or service by trade name, trademark, manufacturer, or otherwise does not necessarily constitute or imply its endorsement, recommendation, or favoring by the United States Government or any agency thereof. The views and opinions of authors expressed herein do not necessarily state or reflect those of the United States Government or any agency thereof. 


\section{DISCLAIMER}

Portions of this document may be illegible in electronic image products. Images are produced from the best available original document. 
for inductor $L_{r 2}$, resonant circuit operation begins when switch $\mathrm{Sr} 2$ is turned on to establish a current, $I_{L r 2}$, in the inductor before turning off the main switches, S2 and S3. Once the inductor current is higher than the load current, the main switch pair can be turned off. When all the main switches are off, resonance occurs between the resonant inductor and resonant capacitors. The capacitor voltage polarity will be changed which diverts the current to the antiparallel diodes. When the anti-paralleled diodes conduct, the voltage across the main switch becomes zero and zerovoltage switching can be realized.

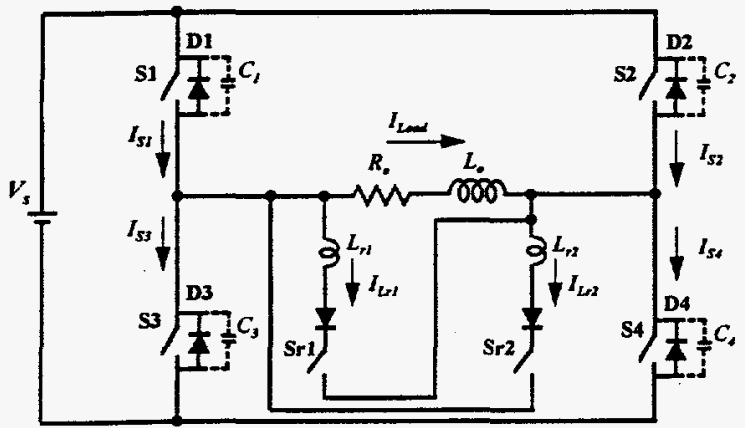

Fig. 3. Single-phase delta connected resonant snubber inverter shown with a series resistor and inductor load.

The step-by-step operation is described below:

Mode 0 or $\left(t_{0} \sim t_{l}\right)$ : The initial condition assumed is for a positive load current which is free-wheeling through D2 and D3 with S2 and S3 conducting.

Mode 1 or $\left(t_{1} \sim t_{2}\right)$ : At $t_{1}$, turn on resonant switch $\mathrm{Sr} 2$. The resonant inductor current, $I_{L, r}$, increases linearly. The current in switches S2 and S3 is correspondingly reduced to zero at time $t_{2}$ when the resonant inductor current equals the load current.

Mode 2 or $\left(t_{2} \sim t_{3}\right):$ The inductor current exceeds the load current after $t_{2}$. When the resonant current increases to twice the load current at $t_{3}$, turn off devices $\mathrm{S} 2$ and $\mathrm{S} 3$. Capacitors $C_{2}$ and $C_{3}$ serve as lossless snubbers to allow zero voltage turn-off.

Mode 3 or $\left(t_{3} \sim t_{4}\right)$ : The resonant capacitors conduct at time $t_{3}$. Capacitors $C_{2}$ and $C_{3}$ are charged to full voltage, $\mathrm{V}_{s}$, and $C_{1}$ and $C_{4}$ are discharged to zero voltage at $t_{4}$.

Mode 4 or $\left(t_{t} \sim t_{s}\right)$ : The resonant current starts to decrease, and the load current is diverted to diodes D1 and D4. Switches $S 1$ and $S 4$ can be turned on at zero voltage condition. At time $t_{5}$, the resonant current equals the load current, and the diode current is diverted to the switch.

Mode 5 or $\left(t_{5} \sim t_{6}\right)$ : The resonant current continues to decrease while the switch current increases linearly. At time $t_{6}$, the resonant current decreases to zero, and resonant switch $\mathrm{Sr} 2$ can be turned off at zero current condition.
Fig. 4 illustrates resonant operation in the different operating modes over one transition cycle consisting of turning on and then turning off the resonant switch. Fig. 5 shows voltage and current waveforms in the different operation modes. The top two traces show load current, $I_{\text {load }}$ and resonant current, $I_{L r 2}$. Waveform $I_{S l, 4}$ shows the current in the switch pair $S 1$ and $S 4$, and waveform $I_{S 2,3}$ shows the current in the switch pair S2 and S3. Capacitor currents are labeled $I_{C_{1,4}}$ and $I_{C 2,3}$, respectively. The main switch turn-on and turn-off signals are labeled $S_{l, 4}$ and $S_{2,3}$, respectively. The switch is on when the signal level is high, and vice versa. The resonant switch switching signal, $S_{r 2}$, indicates the resonant transition period. The scale shown emphasizes the resonant transition period and is not intended to be in proportion to actual timing.
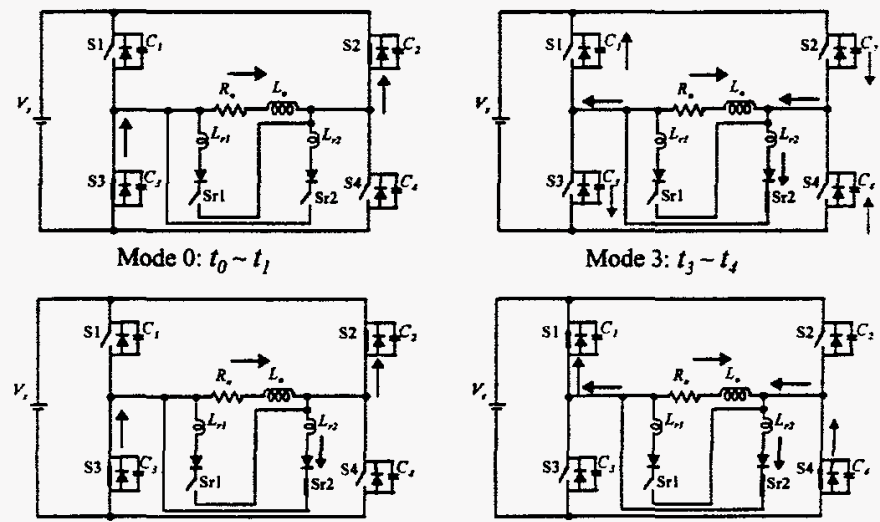

Mode 3: $t_{3}-t_{4}$

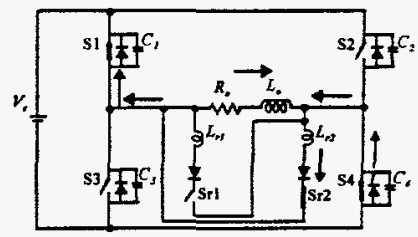

Mode 1: $t_{1} \sim t_{2}$

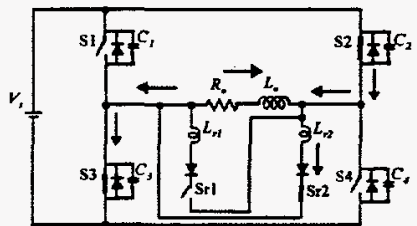

Mode 2: $t_{2} \sim t_{3}$

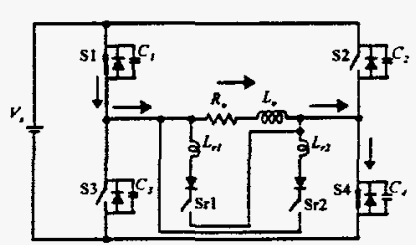

Mode 5: $t_{5}-t_{6}$

Fig. 4. Operating modes of the single-phase delta connected resonant snubber inverter.

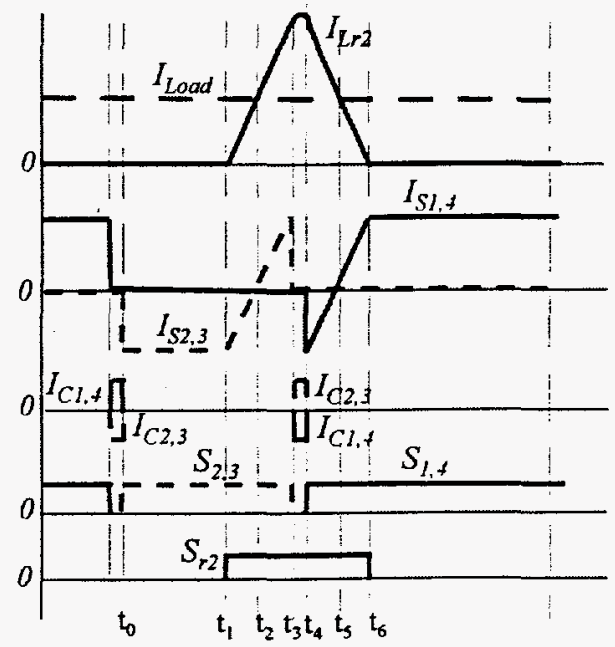

Fig. 5. Voltage and current waveforms in the different operation modes. 


\section{B. Three-Phase Circuit Operation}

For the three-phase inverter shown in Fig. 1, the unidirectional auxiliary switches allow the resonant current to flow only from $\mathbf{a}$ to $\mathbf{b}, \mathbf{b}$ to $\mathbf{c}$, and $\mathbf{c}$ to $\mathbf{a}$. For reverse resonant currents, i.e., from $\mathbf{b}$ to $\mathbf{a}, \mathbf{c}$ to $\mathbf{b}$, and $\mathbf{a}$ to $\mathbf{c}$, two auxiliary switches are turned on simultaneously. For example, to obtain a resonant current from $\mathbf{b}$ to $\mathbf{a}$, turn on switches $\mathrm{Sb}$ and Sc. This type of switching requires complicated logic circuit design and additional turn-on duty of the auxiliary switches. An altemative approach is to add a reverse conducting switch-diode pair in each branch to simplify the logic design and to reduce the conduction duty of the auxiliary switches which allows the use of smaller auxiliary switches. Fig. 6 shows the $\Delta$-configured resonant snubber circuit with bidirectional switches in auxiliary branch circuits. Because the size of the auxiliary switch can be further reduced, the added auxiliary switch cost may be insignificant in the overall system.

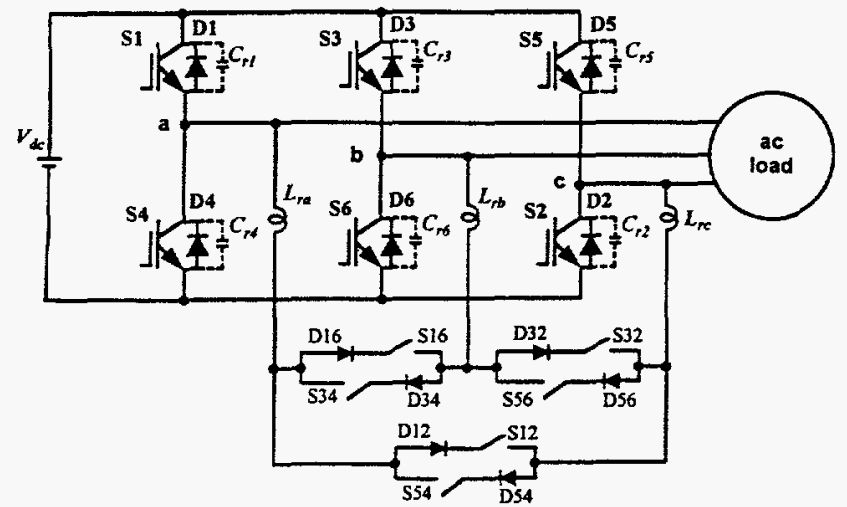

Fig. 6. Bi-directional auxiliary switches are used to simplify switching logic control and to reduce the duty cycle of the auxiliary switches.

Although the circuit may operate with space vector modulation $[4,5]$, the control can be very complicated because it requires sensing both load and resonant currents in the logic design. A more practical way is to employ a nonadjacent state space vector modulation. Fig. 7 illustrates the suggested state transition diagram.

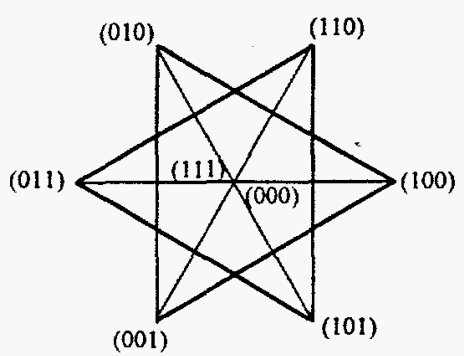

Fig. 7. Non-adjacent state space vector modulation diagram.

For an initial state of (100), i.e., switch S1 is on, and switches S3 and S5 are off, the allowable next state is (010), $(001)$, or $(011)$. Most state transitions are keeping one phase unchanged, and the other two phases operating like a singlephase full bridge inverter (e.g. $100<\rightarrow 010$ for phases a and b, $100<->001$ for phases a and c). Such a state transition is categorized as a $120^{\circ}$ transition. The only state transition $\left(180^{\circ}\right)$ that requires switching all three phases is to change the original state to the opposite direction (e.g. 100<->011).

Such an inverter control scheme is well suited for permanent magnet brushless dc motors because the operation of these motors is divided into six modes, and each mode is to modulate the load current for one positive phase and one negative phase, i.e., $(\mathbf{a},-\mathbf{b}),(\mathbf{a},-\mathbf{c}),(\mathbf{b},-\mathbf{c}),(\mathbf{b},-\mathbf{a}),(\mathbf{c},-\mathbf{a})$, and $(\mathbf{c},-\mathbf{b})$. The current modulation during each mode is exactly like a single-phase full-bridge with only $120^{\circ}$ state transitions allowable. Between mode transitions, there is a need to employ the $180^{\circ}$ space vector transition. The difficulty of the $180^{\circ}$ transition is the unknown switch state of the on-coming phase. If the motor runs only at the motoring mode, the switch state should be predictable. However, if the motor is allowed to operate in the regenerative mode, the switch state should be detected with switch voltage sensing.

In comparison with the optimized state space vector modulation, the non-adjacent state space vector modulation will produce larger current ripples but achieve faster dynamic responses.

\section{HARDWARE IMPLEMENTATION AND EXPERIMENTAL RESULTS}

\section{A. Single-Phase Unit}

A single-phase $1-\mathrm{kW}$ resonant snubber inverter has been built to drive a $1 / 4 \mathrm{hp}$ electric fan. Parameters of the main inverter circuit components are listed below.

S1 S4 : IRFP360

S5 — S6 : IRF740 in series with MUR450

$L_{r l} \sim L_{r 2}: 22 \mu \mathrm{H}$ (\#18 twisted wire, powder iron core)

$C_{r l} \sim C_{r f}: 22 \mathrm{nF}$ (Polypropylene)

For comparison purposes, the inverter implements both hard- and soft- switching functions in a programmable logic device. The control logic has the option of running in the hard-switching mode simply by disabling the auxiliary switch. Fig. 8 shows the oscillograms which compare the different experimental load current results obtained for hardand soft-switching inverters. Apparently high frequency EMI is greatly reduced by the proposed soft-switching method.

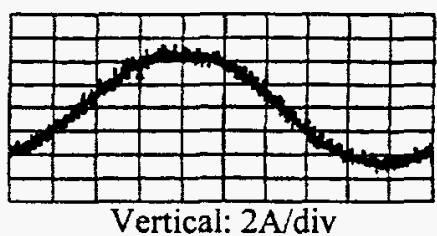

Horizontal: $2 \mathrm{~ms} / \mathrm{div}$

(a) Hard switching

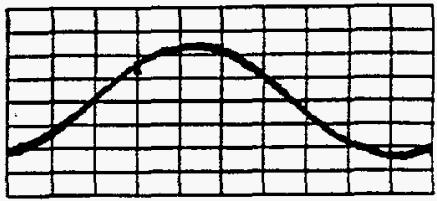

Vertical: 2A/div

Horizontal: $2 \mathrm{~ms} / \mathrm{div}$
Fig. 8. Output current comparison between hard- and soft- switching inverters showing greatly reduced EMI by the proposed technique. 
In addition to greatly reduced EMI, the experimental results also demonstrated major improvements in inverter efficiency $(\eta)$. For $15-\mathrm{kHz}$ PWM switching frequency, efficiency evaluation results are listed in Table I for both the soft-switching (S.S.) and hard-switching (H.S.) modes. The fundamental output frequency, $f_{o}$, was adjusted from $30 \mathrm{~Hz}$ through $75 \mathrm{~Hz}$. At each output frequency, the output power, $P_{o}$, is the same for both soft- and hard-switching inverters.

Table I: Efficiency comparison between soft- and hard- switching inverters

\begin{tabular}{|l|c|c|c|}
\hline$\sigma_{o}(\mathrm{~Hz})$ & $P_{o}(\mathrm{~W})$ & S. S. $\eta(\%)$ & H. S. $\eta(\%)$ \\
\hline 30 & 75 & 82.4 & 66.2 \\
\hline 45 & 142 & 89.7 & 78.3 \\
\hline 60 & 276 & 93.4 & 87.0 \\
\hline 75 & 445 & 96.6 & 93.8 \\
\hline
\end{tabular}

Energy savings at low speeds are more significant than the savings at high speeds because the switching losses increase as machine speed decreases. Fig. 9 shows the efficiency comparison of the inverter operating at hard- and soft- switching modes over the tested speed range (from 30 $\mathrm{Hz}$ to $75 \mathrm{~Hz}$ ). The rated frequency for this electric fan motor is $60 \mathrm{~Hz}$. The efficiency improvement at the half-speed is about $16 \%$, and at the rated speed is about $6 \%$. The efficiency advantage of the soft-switching at speeds higher than the rated speed is gradually diminished because the inverter operation is in the transition from PWM to squarewave mode. The low speed efficiency of the soft-switching inverter can be further improved with variable timing control to vary the charging time of the resonant inductor, which can make a major efficiency improvement over a wide load range for a high power system.

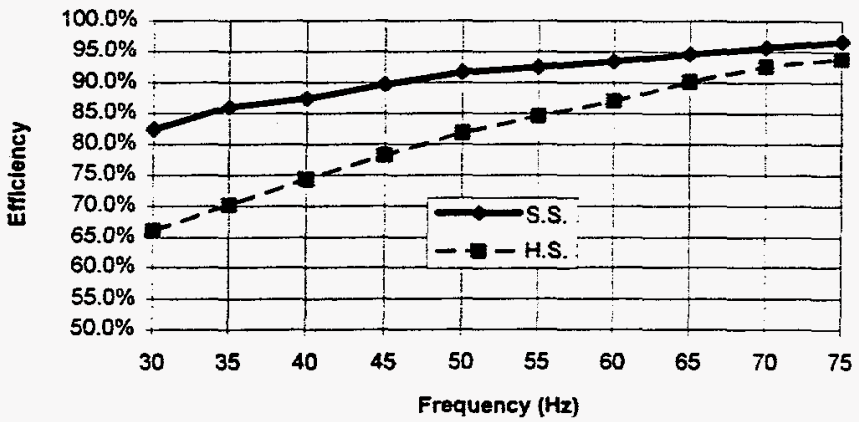

Fig. 9. Efficiency comparison between hard- and soft-switching inverters.

Fig. 10 illustrates the main switch device turn-on and turn-off characteristics under soft-switching condition. During turn-off, the drain-source voltage, $V_{d s}$, rises slowly with a dv/dt of approximately $220 \mathrm{~V} / \mu \mathrm{s}$. This indicates that the turn-off $\mathrm{dv} / \mathrm{dt}$ is manageable by the added external capacitors. Instead of being determined by the device turnoff characteristics, the magnitude of $\mathrm{dv} / \mathrm{dt}$ is determined by $I_{o} /\left(2 C_{r}\right)$ where $I_{o}$ is the device turn-off current and $C_{r}$ is the resonant capacitor across each device. The soft-switching turn-on $\mathrm{dv} / \mathrm{dt}$ rate is similar to its turn-off counterpart except that the direction is different.

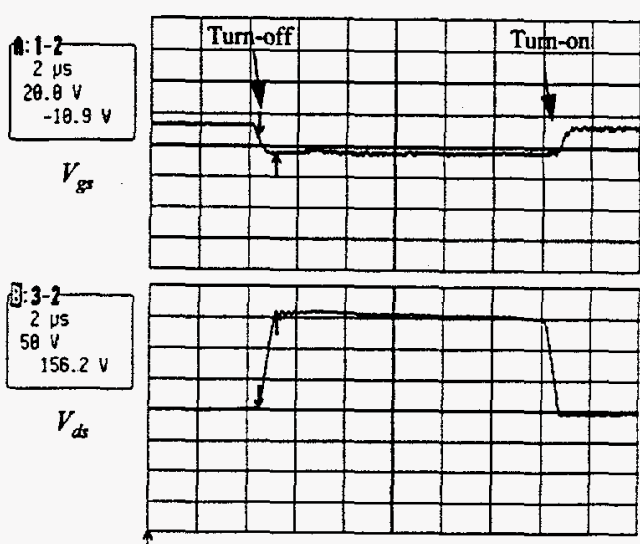

Fig. 10. Device gate-source and drain-source voltages during turn-off showing slow dv/dt characteristic (approximately $220 \mathrm{~V} / \mu \mathrm{s}$ ).

\section{B. Three-Phase Circuit Operation}

Using the circuit shown in Fig. 6, a three-phase 100-kW inverter has been constructed and tested. The inverter is rated $320-\mathrm{V}, 330-\mathrm{A}$, intended for electric vehicle traction drive applications. The unit uses IGBTs as both the main and auxiliary devices. Major inverter circuit components are listed below.

Main devices:

Two single modules (1MBI600LP. 600 and $1 \mathrm{MBI} 600 \mathrm{LN}-600$ ) in series for each phase-leg $(600 \mathrm{~V}, 600 \mathrm{~A})$. Size of a single module $(\mathrm{L} \times \mathrm{W} \times \mathrm{H})$ : $4.25 " \times 2.44 " \times 1 "$ ".

Auxiliary devices: IRGPC50FD2 (600 V, 39 A), with two in anti-series for each branch, shown in Fig. 11. Size of a single device $(\mathrm{L} \times \mathrm{W} \times \mathrm{H}): 0.8 " \times 0.6 " \times 0.2^{\prime \prime}$.

Inductors $L_{r a}, L_{r a}, L_{r}: 1 \mu \mathrm{H}$ (Copper strip with magnetic shield).

Capacitors $C_{r j} \sim C_{r 6}: 0.27 \mu \mathrm{F}$ (Polypropylene).

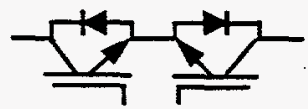

Fig. 11. Structure of the auxiliary switch combination for each branch

It should be noted that the conduction duty of the auxiliary device is very low as compared to that of the main device. For a trapezoidal brushless dc motor, the auxiliary switching frequency is even lower. Using Fig. 6 as the example, auxiliary switches $\$ 16$ and $\$ 34$ only operate during modes $(\mathbf{a},-\mathbf{b})$ and $(\mathbf{b},-\mathbf{a})$ for $\mathbf{a}$ brushless dc motor. This implies that the switching frequency of each auxiliary switch is $1 / 6$ the PWM frequency. For $20-\mathrm{kHz}$ switching frequency (50- $\mu$ s switching period), if the maximum auxiliary switch turn-on time is $6 \mu \mathrm{s}$, the overall turn-on duty of the auxiliary switch is only $2 \%$. At the rated load condition $(100 \mathrm{~kW})$, the peak resonant current is less than $500 \mathrm{~A}$, and the average auxiliary switch rms current will be less than $10 \mathrm{~A}$. The 39A device has more than enough rms current handling 
capability for this specific design. The only concern is the dynamic voltage drop at such a peak current. For a better inverter efficiency, a constant voltage drop and high pulse current handling device such as a MOSFET Controlled Thyristor (MCT) is a better choice for the auxiliary switch. Nevertheless, the selected IGBT (IRGPC50FD2) works satisfactorily with this $100-\mathrm{kW}$ inverter prototype.

Fig. 12 shows a photograph of the $100-\mathrm{kW}$ inverter packaged in a notebook size. A 14-layer printed circuit board (serving as a high frequency capacitor) holds the dc bus capacitors and is mounted on top of the main devices to reduce the parasitic inductance as much as possible. The gate drives are mounted directly on top of the main devices, and the control circuitry (not shown) will be stacked on top of the dc bus capacitors. The resonant inductor is nothing but a copper strip connected from the auxiliary switch to the ac output bus bars. The copper strip inductance, approximately $0.5 \mu \mathrm{H}$, is so high that a small magnetic shield comprising four toroid powder iron cores will sufficiently achieve the required inductance. The size of the auxiliary device is only a fraction of the main device. As indicated in the picture, the physical size of the total six auxiliary devices along with their gate drivers is smaller than one main device. As compared to the traditional passive snubber (diode+capacitor+big resistor), the resonant snubber (switch+capacitor+small inductor) dramatically reduces the physical size. For commercial production, the physical size can be further reduced with surface mount components.

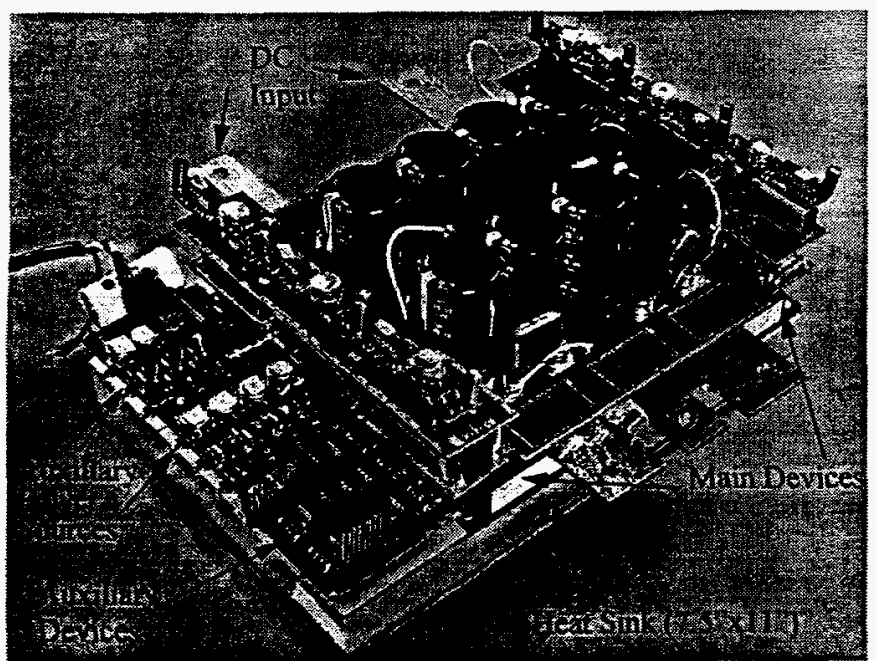

Fig. 12. Photograph showing a $100-\mathrm{kW} \Delta-$-configured resonant snubber based inverter.

Before being configured into the soft-switching mode, the unit was tested in the hard switching mode with dc bus capacitors $(2000-\mu \mathrm{F}$ electrolytic plus $20-\mu \mathrm{F}$ polypropylene) as snubbers, and the resonant capacitors were disconnected . The resulting device turn-off voltage and load current waveforms are shown in Fig. 13. At $200-\mathrm{V}$ dc input voltage and 75-A load current, $I_{\text {Lood, }}$, the device (S4) collector-emitter voltage, $V_{c e-S t}$, presents a high switching $\mathrm{dv} / \mathrm{dt}$ of approximately $3000 \mathrm{~V} / \mu \mathrm{s}$ and a $50 \%$ voltage overshoot. The voltage overshoot will be worse at higher current conditions. A possible way of reducing voltage overshoots is to add more dc bus capacitors (both electrolytic and polypropylene) which will add to the cost penalty too. The switching dv/dt remains high even with large de link capacitors.

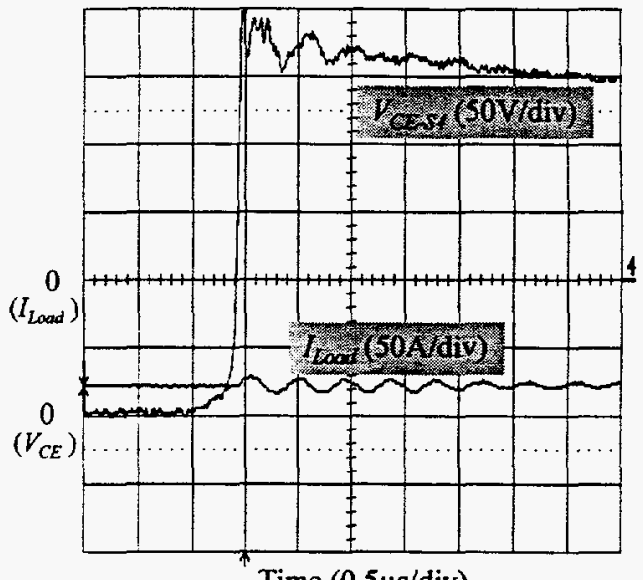

Time $(0.5 \mu \mathrm{s} / \mathrm{div})$

Fig. 13. Hard-switching collector-emitter voltage and load current during turn-off showing high $\mathrm{dv} / \mathrm{dt}$ characteristic $(3000 \mathrm{~V} / \mu \mathrm{s})$.

After reconfiguring into the soft-switching mode, the unit was tested at different voltage levels and modulation indices. The inductor charging time is controllable in this three-phase unit, and the complete three-phase inverter control is implemented in a programmable logic device. At about the same load current level $(70 \mathrm{~A})$ as tested in the hardswitching mode, but a higher dc bus voltage $(250 \mathrm{~V})$, experimental load current, $I_{\text {Lood, }}$, resonant current, $I_{\text {Lra }}$ and two device voltages, $V_{c e-S t}$ and $V_{c e-S 6}$, waveforms are shown in Fig. 14. For a turn-off current of $300 \mathrm{~A}$, the device turnoff $\mathrm{dv} / \mathrm{dt}$ is about $560 \mathrm{~V} / \mu \mathrm{s}$, and the voltage overshoot is about $10 \%$. This result proves that the resonant snubber based soft-switching inverter alleviates several problems experienced in the traditional hard switching inverters.

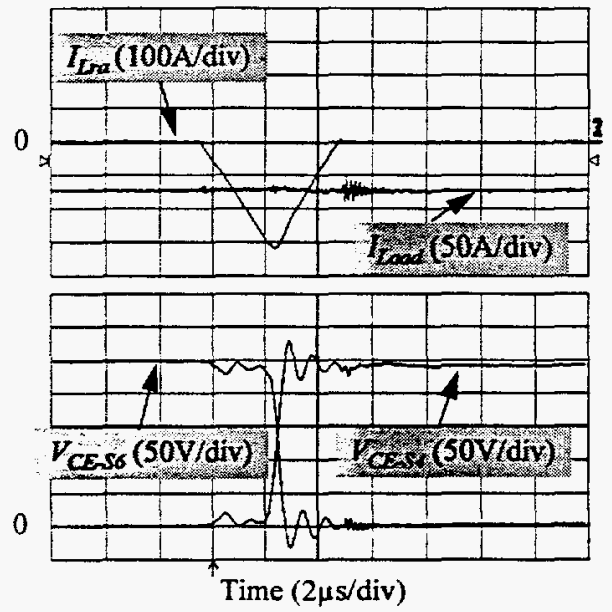

Fig. 14. Soft-switching collector-emitter voltage and load current during tum-off showing low $\mathrm{dv} / \mathrm{dt}$ characteristic $(300 \mathrm{~V} / \mu \mathrm{s})$. 
The device voltage tends to oscillate during switching due to a sharp resonant current change rate (di/dt) interacting with the leakage inductance of the dc bus capacitor. This voltage ringing does not occur in the single-phase unit because the single-phase unit has a much larger resonant inductor to limit the $\mathrm{di} / \mathrm{dt}$ on the resonant branch. Although this voltage ringing can be reduced by a larger resonant inductance, it needs to have a longer charging time to achieve zero-voltage switching, meaning more duty for the auxiliary switch. The use of better dc bus capacitors can also help reduce the ringing, but it will incur a cost penalty.

Fig. 15 shows three resonant inductor currents when switches S34 and S54 are turned on for the transition from $(\mathrm{S} 4, \mathrm{S3}, \mathrm{S} 5)$ to $(\mathrm{S} 1, \mathrm{~S} 6, \mathrm{~S} 2)$. The resonant currents of phases $b$ and $\mathbf{c}$ are slightly mismatched due to possible unequal inductances between phases and different time responses of instruments used in this measurement.

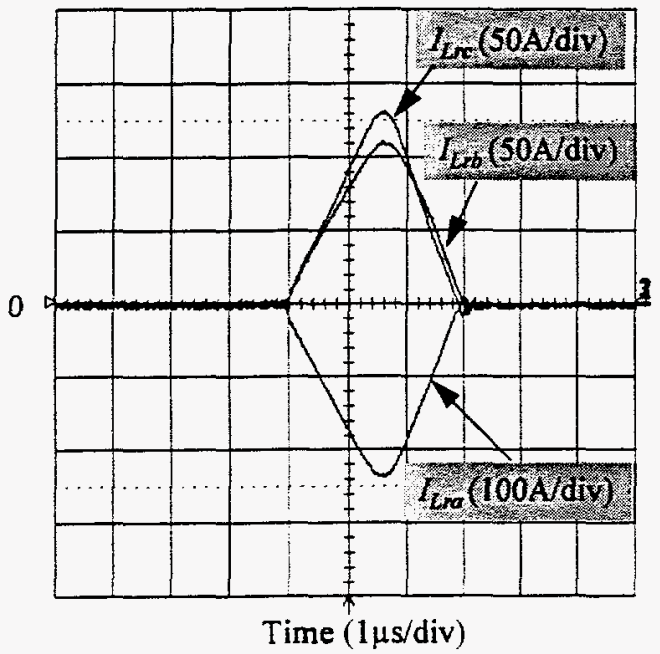

Fig. 15. Resonant inductor currents during mode transition.

\section{DISCUSSION AND CONCLUSION}

A delta configured auxiliary resonant snubber inverter has been proposed for high performance power conversion applications. Major benefits of this new inverter are found in efficiency improvement, greatly reduced EMI, and reduced $\mathrm{dv} / \mathrm{dt}$.

In comparison with the auxiliary resonant snubber inverters in $[1,4,5]$, the proposed scheme presents the following advantages:

- no floating voltage or over-voltage penalty on the auxiliary switches,

- no circulating current in the off phase, and

- no need for anti-paralleled fast recovery diodes across the resonant switches.

In comparison with the ARCP inverter, the proposed topology avoids the need for additional dc bus bulky capacitors. In comparison with the traditional snubber-less hard-switching inverter, the proposed method can reduce the voltage overshoot for the same amount of $\mathrm{dc}$ bus capacitors in addition to largely reduced EMI and dv/dt and improved efficiency. In comparison with the passive snubber based inverter, the proposed method avoids the bulky dissipative resistor and largely improves efficiency.

The proposed inverter concept has been proven with computer simulation and hardware implementation. It should be noted that a 39-A auxiliary device can operate at a peak pulse current of more than 400-A with a small duty cycle. The reduction of the switching loss, in fact, allows the main device to be operated at a higher current condition. Such a device utilization is the key to inverter size and cost reduction. The experimental resonant snubber inverters not only present improvement of the system performance, but also improvement of the power density through reduction of the heat sink and dc bus capacitors. Possible cost reduction can also be realized with better utilization of the switching devices.

The proposed inverter is most suitable for trapezoidal back emf brushless dc motor drives. Because these machines operate with only two phases conducting simultaneously while leaving one phase completely off, some resonant snubber based circuit topologies can have unexpected circulating currents in the off-phase winding. The proposed inverter avoids these circulating currents with minimum auxiliary components. It operates like a traditional PWM inverter in both the motoring and regenerating modes without over-voltage or over-current penalties which are found in other resonant link technologies. The single-phase version can be used in uninterruptible power systems (UPS) and bidirectional dc motor drives. Both single-phase and threephase versions are suitable for motor drives and utility power line conditioners used to compensate reactive power and harmonics. Future work can be directed to these applications and their performance evaluation.

\section{REFERENCES}

[1] J. S. Lai, R. W. Young, Sr., G. W. Ott, C. P. White, J. W. McKeever, and D. S. Chen, "A novel resonant snubber inverter," in Conference Record of IEEE Applied Power Electronics Conjerence, March 1995, pp. 797-803.

[2] R. W. DeDoncker and J. P. Lyons, "The auxiliary quasi-resonant dc link inverter," in Conference Record of IEEE Power Electronics Specialists Conference, June 1991, pp. 248-253.

[3] W. McMurray, "Resonant snubbers with auxiliary switches," IEEE Trans. on Industry Applications, Vol. 29, No. 2, March/April 1993, pp. 355-362.

[4] V. Vlatovic, D. Borojevic, F. C. Lee, C. Cuadros, and S. Gataric, "A new zero-voltage transition, three-phase PWM rectifier/inverter circuit." Conference Records of IEEE Power Electronics Specialists Conference, June 1993, pp. 868-873.

[5] C. Cuadros, D. Borojevic, S. Gataric, V. Vlatovic, H. Mao, F. C. Lee, "Space vector modulated, zero-voltage transition three-phase to dc bidirectional converter," Conference Records of IEEE Power Electronics Specialists Conference, June 1994, pp. 16-23. 